\title{
Anne Boutin, Parole, personnage et sujet dans les récits littéraires de Benjamin Constant
}

\section{Catherine Thomas}

\section{(2) OpenEdition}

10 Journals

\section{Édition électronique}

URL : https://journals.openedition.org/studifrancesi/3129

DOI : 10.4000/studifrancesi.3129

ISSN : 2421-5856

Éditeur

Rosenberg \& Sellier

\section{Édition imprimée}

Date de publication : 1 juillet 2013

Pagination : 466-467

ISSN : 0039-2944

\section{Référence électronique}

Catherine Thomas, «Anne Boutin, Parole, personnage et sujet dans les récits littéraires de Benjamin

Constant », Studi Francesi [En ligne], 170 (LVII | II) | 2013, mis en ligne le 30 novembre 2015, consulté le 02 février 2023. URL : http://journals.openedition.org/studifrancesi/3129; DOI : https://doi.org/ 10.4000/studifrancesi.3129

Ce document a été généré automatiquement le 2 février 2023.

\section{(c)}

Creative Commons - Attribution - Pas d'Utilisation Commerciale - Pas de Modification 4.0 International - CC BY-NC-ND 4.0

https://creativecommons.org/licenses/by-nc-nd/4.0/ 


\title{
Anne Boutin, Parole, personnage et sujet dans les récits littéraires de Benjamin Constant
}

\author{
Catherine Thomas
}

\section{RÉFÉRENCE}

ANNE BOUTIN, Parole, personnage et sujet dans les récits littéraires de Benjamin Constant, Slatkine, 2008, pp. 589.

1 Le titre même de la thèse d'Anne Boutin, préfacée par Gérard Gengembre, indique assez que son étude s'inscrit dans la droite ligne de celles qui contribuèrent au renouvellement de la critique constantienne en reconnaissant l'importance majeure de la parole dans l'univers du romancier. Cependant, si les études critiques ont jusqu'ici insisté sur l'échec de la parole chez des personnages en crise, Anne Boutin s'attache davantage à montrer comment Benjamin Constant, dans Amélie et Germaine, Cécile, Ma vie et Adolphe, exploite toutes les ressources de la parole pour finalement en faire l'éloge.

2 La première partie, intitulée «Récits constantiens: entre récit de vie et recréation de la vie», établit l'importance de la parole du narrateur, qui se révèle toujours être le protagoniste masculin du récit, et les modalités selon lesquelles elle s'inscrit dans les textes. Anne Boutin montre comment chacune de ces œuvres, avec les variantes qui lui sont propres, se structure par la voix du sujet parlant. Entre autobiographie, journal intime et roman, le texte manifeste une sorte de flottement à travers des écritures qui explorent différentes façons d'appréhender la complexité du sujet en même temps qu'elles dévoilent les difficultés de cette entreprise. Ainsi les oscillations génériques traduisent-elles à la fois les recherches d'un auteur qui joue sur l'imperceptible écart, au sein duquel se construit l'œuvre littéraire, entre vie réelle et fiction, et les faiblesses d'un nouveau type de personnage, en proie aux doutes et aux incertitudes. 
3 S'intéressant ensuite aux représentations des échanges verbaux, Anne Boutin souligne dans les récits inachevés, Amélie et Germaine, Cécile et Ma Vie, l'omniprésence et la toutepuissance de la voix narrative qui organise la diégèse et tente de donner un sens au vécu, laissant peu de place aux paroles des personnages. Cette soumission du récit au point de vue d'un «je» traduit encore la fragilité du protagoniste, pour sa part incapable de maîtriser la parole, et sa difficulté à se constituer en tant que sujet. Les voix sont plus variées dans Adolphe, puisque le roman est encadré de textes introductifs et conclusifs qui en orientent et en complexifient la lecture, et que le narrateur restitue la parole de plusieurs personnages. Pour autant, le protagoniste reste silencieux, et c'est encore la voix de l'auteur, dont elle module les variations, que cette pluralité donne sans doute à entendre. Ainsi l'écriture des paroles et leur introduction dans le texte, très finement étudiées par Anne Boutin, révèlent-elles des choix esthétiques qui ont une incidence sur notre perception des personnages, mais aussi sur l'interprétation générique des œuvres, plus ou moins proches de la fiction selon l'importance accordée à la parole des personnages.

4 Dans la troisième partie («Une auscultation de la langue conventionnelle») la parole est considérée comme représentative d'une société dominée par des règles et des codes, telle que l'a vraisemblablement connue Benjamin Constant: c'est ce qu'Anne Boutin appelle la «langue conventionnelle», en soulignant la place considérable qu'elle prend dans ces récits littéraires puisqu'elle influe sur l'intrigue et sur les personnages, et qu'elle se situe au croisement du public et du privé, au point où il s'agit d'affirmer sa singularité tout en s'inscrivant dans une norme. Constant nous propose d'étudier une langue dont il ne produit, paradoxalement, aucun exemple, et qu'il présente comme inutile et vaine: réduite à l'expression d'un «on» dont l'identité importe moins que le caractère dangereux et pesant de son discours, elle apparait gonflée d'automatismes et de lieux communs, lieu de médisance et de rumeurs, parfois associée à un discours amoureux convenu, jusqu'à se trouver vidée de sa substance.

Enfin, Anne Boutin s'interroge sur la place du silence et de l'écriture épistolaire dans les quatre textes étudiés pour mieux comprendre les spécificités et la complexité de la parole, dont elle montre cette fois les richesses. En dépit des difficultés éprouvées par les personnages dans le maniement du langage, Constant souligne le pouvoir des mots et le rôle qu'ils jouent dans la constitution du sujet, ainsi que dans la transformation de la réalité. Anne Boutin montre que c'est finalement une même histoire qui se décline à travers ces récits littéraires, selon des modalités diverses: celle «d'un sujet qui voulait parler et qui n'y parvenait pas». Cette histoire révèle les hésitations et les doutes inhérents à chacun des personnages-narrateurs, mais reflète également les tentatives de l'auteur pour dire sa propre vérité et inviter le lecteur à comprendre les difficultés de la parole pour mieux croire en ses potentialités. Elle dit aussi l'absence de repères et la perte des valeurs qui marquent la société française à l'aube du xIX siècle, saisie dans la conscience d'une subjectivité. Dans sa volonté de dévoiler toutes les caractéristiques et les manifestations de la parole dans les quatre œuvres qu'elle étudie, Anne Boutin n'évite pas la répétition fréquente des mêmes citations, et ne ménage pas toujours ses transitions; elle montre pourtant parfaitement et avec finesse, dans un travail d'une remarquable clarté et richement annoté, toutes les subtilités de la langue de Benjamin Constant, et la profonde modernité de ses textes. 